$\xi_{p}$

\title{
Evaluation of NSE Price Data Using Reliability of Series Structure Model
}

\author{
Abdul Razak K ${ }^{1 *}$, Rajakumar $K^{2}$ \\ ${ }^{l}$ Department of Mathematics, M.Kumarasamy College of Engineering (Autonomous), \\ Karur, Tamil Nadu, India. \\ ${ }^{2}$ Department of Mathematics, Trichy Engineering College, Trichy, Tamil Nadu, India. \\ *Corresponding author E-mail: arrazak76@gmail.com
}

\begin{abstract}
Fluffy set based techniques have been turned out to be successful in taking care of numerous kinds of vulnerabilities in various fields, including dependability building. In any modern system, the reliability and cost are considered to be the most important factor and the reliability of the system may be twisted as linear or nonlinear programming. This paper deals the fluffy nonlinear reliability optimization problem for series structure model. The objective of this paper is to quantify the most extreme unwavering quality subject to leat cost using triangular fluffy number. As an illustration, system of five components NSE price data is analyzed
\end{abstract}

Keywords: Fluffy sets, Reliability, Series structure, Triangular fluffy number, Fluffy Non-linear Programming

\section{Introduction}

The Reliability optimization provides help to the reliability engineer to get the finest manner to enhance the reliability of the system. Reliability is a gauge of the result for the quality of the product in the long run. Reliability of product is not identified before the outcome and it is based on its constraints such as cost, weight etc. The constraint of reliability problems can be involved in uncertain factors and it can be represented by fluffy number. Shi et al [9] presented the reliability performances for a cold standby series structure by using empirical Bayesian and multiple Bayesian methods. Nabil Nahas et al [6] analyzed an application of ant system in reliability for a series structure to maximize the system reliability subject to the system budget. Yuan et al [11] and Benjamin Epstein et al [2] have investigated special techniques and solutions on series structure in different situation.

Abdul Razak at al [1] presented the parallel system model to evaluate the maximum reliability using co-efficient of variance. Ruan \& Sun [8] offered a correct method for least cost problem in series reliability system with several element choices. Mahapatra et al [5] presented fluffy reliability problem of series structure model in the course of fluffy parametric geometric programming using max-min and max additive operator.

Sung et al [10] used a reliability optimization problems for a series structure with multiple-choice to most extreme unwavering quality subject to least cost of the system. Ezzatallah et al [3] analyzed reliability of the fluffy system of a series and parallel system, using fluffy confidence interval. Lee et al [4] analyzed the Reliability of a parallel system using $(\lambda, \rho)$ interval valued fluffy numbers.

This paper isdeveloped as pursues. Segment 2 expresses the documentations and fluffy sciences essentials. The scientific plan in fresh model and fluffy model are examined in segment 3 .The mathematical investigation is described in segment 4 . The solution process for the series structure models are discussed in segment 5 .
Segment 6 considers numerical implementation that evaluates the reliability of series structure. Conclusion has been discussed in segment 7 .

\section{Mathematical model}

\subsection{Notations}

$\mathrm{R}_{\mathrm{i}} \quad$ - Reliability of ith component for

$\mathrm{i}=1,2, \ldots \mathrm{m}$

$\mathrm{C}_{\mathrm{i}} \quad-$ Cost of ith component of reliability for

$\mathrm{i}=1,2, \mathrm{~m}$

$\mathrm{R}_{\mathrm{S}}\left(\mathrm{R}_{1}, \mathrm{R}_{2}, \mathrm{R}_{3} \ldots . . \mathrm{R}_{\mathrm{m}}\right) \quad$ - System reliability of $\mathrm{m}$ components with reliability $R_{i}, i=1,2, \ldots . m$

$\mathrm{C}_{\mathrm{S}}\left(\mathrm{R}_{1}, \mathrm{R}_{2}, \mathrm{R}_{3} \ldots \ldots \mathrm{R}_{\mathrm{m}}\right)$ - System cost of $\mathrm{m}$ components with reliability $R_{i}, \quad i=1,2, \ldots . m$

The reliability for the Series structure is

$\mathrm{R}_{\mathrm{S}}\left(\mathrm{R}_{1}, \mathrm{R}_{2}, \mathrm{R}_{3} \ldots \mathrm{R}_{\mathrm{m}}\right)=\prod_{\mathrm{i}=1}^{\mathrm{m}} \mathrm{R}_{\mathrm{i}}$

The linear cost components are represented by

$$
C_{S}\left(R_{1}, R_{2}, R_{3} \ldots R_{m}\right)=\sum_{i=1}^{m} c_{i} R_{i}, c_{i} \geq 0
$$

\subsection{Fluffy mathematics prerequisites}

A triangular fluffy number $\tilde{A}=\left(a_{1}, a_{2}, a_{3}\right)$ is a fluffy set on $\mathrm{R}$ with the membership function $\mu_{\tilde{A}}(x): X \rightarrow[0,1]$ is defined as

$$
\mu_{\tilde{A}}(x)=\left\{\begin{array}{ccc}
\frac{x-a_{1}}{a_{2}-a_{1}} & \text { if } & a_{1} \leq x \leq a_{2} \\
\frac{a_{3}-x}{a_{3}-a_{2}} & \text { if } & a_{2} \leq x \leq a_{3} \\
0 & & \text { otherwise }
\end{array}\right.
$$

Copyright $\odot 2018$ Authors. This is an open access article distributed under the Creative Commons Attribution License, which permits unrestricted use, distribution, and reproduction in any medium, provided the original work is properly cited. 


\section{Mathematical formulation}

\subsection{Crisp model}

The series structure model is considered with $\mathrm{m}$ components. To quantify the most extreme of reliability $R_{S}\left(R_{1}, R_{2}, R_{3} \ldots R_{m}\right)$ subject to least cost $\mathrm{C}$ in nonlinear programming problem is

$$
\begin{array}{ll}
\text { Maximize } & R_{S}\left(R_{1}, R_{2}, R_{3} \ldots . . R_{m}\right)=\prod_{i=1}^{m} R_{i} \\
\text { Subject to } & C_{S}\left(R_{1}, R_{2}, R_{3} \ldots . . R_{m}\right)=\sum_{i=1}^{m} c_{i} R_{i} \leq C
\end{array}
$$

\subsection{Fluffy model}

In practice the cost factor plays a key role in reliability analysis and it can be concerned in undecided factors. So the reliability of this structure subject to the fluffy cost is

Maximize $R_{S}\left(R_{1}, R_{2}, R_{3} \ldots R_{m}\right)=\prod_{i=1}^{m} R_{i}$

Subject to $C_{S}\left(R_{1}, R_{2}, R_{3} \ldots R_{m}\right)=\sum_{i=1}^{m} \tilde{c}_{i} R_{i} \leq \tilde{C}, 0<R_{i} \leq 1$

\section{Mathematical analysis}

A non-linear programming problem having one inequity constraint is

Maximize $\quad \mathrm{Z}=\mathrm{f}\left(\mathrm{x}_{1}, \mathrm{x}_{2} \ldots \ldots . \mathrm{x}_{\mathrm{n}}\right)$

Subject to

$$
h(X) \leq 0 \text { where } h(X)=g\left(x_{1}, x_{2} \ldots x_{n}\right)-b, h(X) \geq 0
$$

By Kuhn-Tucker condition in Premkumar Gupta et al (7), the essential conditions for the maximization of non-linear programming problem is expressed as

$\frac{\partial f}{\partial x_{j}}-\lambda \frac{\partial h}{\partial x_{j}}=0$

$\lambda \mathrm{hX})=0$, where $\mathrm{h}(\mathrm{X}) \leq 0$ and $\lambda \geq 0$

\section{Solution procedure for reliability of series structure models}

Step 1:Let the cost co-efficient be $\tilde{c}_{i}=\left(c_{i 1}, c_{i 2}, c_{i 3}\right)$ for $\mathrm{i}=1,2 \ldots \mathrm{n}$ and the cost constraint be $\tilde{C}=\left(C_{1}, C_{2}, C_{3}\right)$ be in use as Triangular fluffy number.

Step 2:Using $\alpha$-cut membership function , the fluffy cost coefficient is $\tilde{c}_{i}=\left[c_{i 1}+\alpha\left(c_{i 2}-c_{i 1}\right), c_{i 3}-\alpha\left(c_{i 3}-c_{i 2}\right)\right]$ and fluffy

cost constraint is $\tilde{C}=\left[C_{1}+\alpha\left(C_{2}-C_{1}\right), C_{3}-\alpha\left(C_{3}-C_{2}\right)\right]$

Step 3: Applying the Kuhn-Tucker condition in a fluffy non-linear programming problem for the series structure model of left and right interval $\alpha$-cut is expressed as

Maximize $\quad R_{S}^{L}\left(R_{1}^{L}, R_{2}^{L}, R_{3}^{L} \ldots R_{m}^{L}\right)=\prod_{i=1}^{m} R_{i}^{L}$

Subject to $\quad \sum_{i=1}^{m} \tilde{c}_{i}^{L} R_{i}^{L}-\tilde{C}^{L} \leq 0$,

where $0<R_{i}^{L} \leq 1, \tilde{c}_{i}^{L}$ and $\tilde{C}^{L} \geq 0$

Maximize $\quad R_{S}^{R}\left(R_{1}^{R}, R_{2}^{R}, R_{3}^{R} \ldots ._{m}^{R}\right)=\prod_{i=1}^{m} R_{i}^{R}$

Subject to $\quad \sum_{i=1}^{m} \tilde{c}_{i}^{R} R_{i}^{R}-\tilde{C}^{R} \leq 0$, where $0<R_{i}^{R} \leq 1, \tilde{c}_{i}^{R}$ and $\tilde{C}^{R}>0$

Step 4: $\quad$ To find out the optimal solution of $R_{i}^{L}$ and $R_{i}^{R}$ $\mathrm{i}=1,2 \ldots \mathrm{m}$ and to calculate the system of reliability $R_{S}^{L}=\prod_{i=1}^{m} R_{i}^{L}$ and $R_{S}^{R}=\prod_{i=1}^{m} R_{i}^{R}$ for each membership value of $\alpha$.

Step 5: $\quad$ From the membership value of $\alpha$ to evaluate the maximum reliability.

\section{Numerical example}

The National Stock Exchange value of ICICI bank is illustrated as an example. The historic Prices of ICICI Bank is downloading from the website:

http://www.moneycontrol.com/stocks/companydetails/histdata.php. The NSE price data for ICICI bank dated from 06/06/2016 to $10 / 06 / 2016$ is considered tabulated as

\begin{tabular}{|c|c|c|c|c|}
\hline Date & Open Price & High Price & Low Price & Close Price \\
\hline $06-06-2016$ & 243.40 & 246.00 & 242.00 & 253.50 \\
\hline $07-06-2016$ & 245.50 & 254.85 & 244.70 & 254.10 \\
\hline $08-06-2016$ & 255.20 & 261.20 & 252.80 & 257.65 \\
\hline $09-06-2016$ & 257.00 & 259.25 & 253.20 & 254.55 \\
\hline $10-06-2016$ & 253.00 & 257.65 & 251.50 & 252.60 \\
\hline
\end{tabular}

This naturally shows that, the five components (date) of series structure and the cost values are uncertain in nature. Let us consider the Low price, Close price and High price value as the cost parameter and it is represented by triangular fluffy number

Step 1: $\quad$ The cost co-efficient is $\mathrm{c}_{1}=(242.0,253.50,246.0)$, $\mathrm{c}_{2}=(244.70,254.10,54.85)$,

$c_{3}=(252.80,257.65,261.20)$,

$\mathrm{c}_{4}=(253.20,254.55,259.25)$ and

$c_{5}=(251.50,252.60,257.65)$.

The cost constraint is

$\tilde{C}=(1120.00,1180.50,1215.00)$

Step 2: Using $\alpha$-cut membership function the cost co-

\begin{tabular}{|c|c|}
\hline Cost components & Cost constraints \\
\hline $\begin{aligned} c_{1}= & \left(c_{1}^{L}, c_{2}^{R}\right) \\
& =(242.00+1.50 \alpha, 246.00-2.50 \alpha) \\
c_{2}= & \left(c_{2}^{L}, c_{2}^{R}\right) \\
& =(244.70+9.40 \alpha, 254.85-0.75 \alpha) \\
c_{3}= & \left(c_{3}^{L}, c_{3}^{R}\right) \\
& =(252.80+4.85 \alpha, 261.20-3.55 \alpha) \\
c_{4}= & \left(c_{4}^{L}, c_{4}^{R}\right) \\
& =(253.20+1.35 \alpha, 259.25-4.70 \alpha) \\
c_{5}= & \left(c_{5}^{L}, c_{5}^{R}\right) \\
& =(251.50+1.10 \alpha, 257.65-5.05 \alpha)\end{aligned}$ & $\begin{array}{c}C=\left(C^{L}, C^{R}\right) \\
=(1120.00+60.50 \alpha \\
1215.00-34.50 \alpha)\end{array}$ \\
\hline
\end{tabular}
efficient and constraints of left and right interval value are tabulated as

Step 3: The optimal solution of a fluffy non-linear programming problem with five components of left and right interval $\alpha$-cut can be expressed as follows. The left interval $\alpha$ cut is

$\frac{\partial}{\partial R_{i}^{L}}\left[R_{S}^{L}\right]=\lambda\left[\frac{\partial}{\partial R_{i}^{L}}\left(\tilde{c}_{1}^{L} R_{1}^{L}+\tilde{c}_{2}{ }^{L} R_{2}^{L}+\tilde{c}_{3}{ }^{L} R_{3}^{L}+\tilde{c}_{4}{ }^{L} R_{4}^{L}+\tilde{c}_{5}{ }^{L} R_{5}^{L}\right)-C^{L}\right]$

where $\mathrm{R}_{\mathrm{S}}^{\mathrm{L}}=\mathrm{R}_{1}^{\mathrm{L}} \mathrm{R}_{2}^{\mathrm{L}} \mathrm{R}_{3}^{\mathrm{L}} \mathrm{R}_{4}^{\mathrm{L}} \mathrm{R}_{5}^{\mathrm{L}}$

$\left(\tilde{c}_{1}^{L} R_{1}^{L}+\tilde{c}_{2}{ }^{L} R_{2}^{L}+\tilde{c}_{3}{ }^{L} R_{3}^{L}+\tilde{c}_{4}{ }^{L} R_{4}^{L}+\tilde{c}_{5}{ }^{L} R_{5}^{L}\right)-C^{L}=0$

Similarly, the right interval $\alpha$-cut is 


$$
\begin{aligned}
& \frac{\partial}{\partial R_{i}^{R}}\left[R_{S}^{R}\right]=\lambda\left[\frac{\partial}{\partial R_{i}^{R}}\left(\tilde{c}_{1}^{R} R_{1}^{R}+\tilde{c}_{2}{ }^{R} R_{2}^{R}+\tilde{c}_{3}{ }^{R} R_{3}^{R}+\tilde{c}_{4}{ }^{R} R_{4}^{R}+\tilde{c}_{5}{ }^{R} R_{5}^{R}\right)-C^{R}\right] \\
& \text { where } R_{S}^{R}=R_{1}^{R} R_{2}^{R} R_{3}^{R} R_{4}^{R} R_{5}^{R} \\
& \left(\tilde{c}_{1}^{R} R_{1}^{R}+\tilde{c}_{2}{ }^{R} R_{2}^{R}+\tilde{c}_{3}{ }^{R} R_{3}^{R}+\tilde{c}_{4}{ }^{R} R_{4}^{R}+\tilde{c}_{5}{ }^{R} R_{5}^{R}\right)-C^{R}=0
\end{aligned}
$$

Step 4: Applying left interval value of cost co-efficient and cost constraint in the equations (5) and (6) and right interval value of cost co-efficient and cost constraint in the equations (7) and (8) respectively and solving them then the reliability values are obtained and listed in the table 1 and 2.

Table 1: Left interval optimal solution of NSE price data

\begin{tabular}{|c|c|c|c|c|c|c|}
\hline$\alpha$ & $R_{1}^{L}$ & $R_{2}^{L}$ & $R_{3}^{L}$ & $R_{4}^{L}$ & $R_{5}^{L}$ & $R_{S}^{L}$ \\
\hline 0.0 & 0.9256198 & 0.9154066 & 0.8860760 & 0.8846761 & 0.8906558 & 0.5915778 \\
\hline 0.2 & 0.9344614 & 0.9182415 & 0.8922252 & 0.8932813 & 0.8994915 & 0.6151459 \\
\hline 0.4 & 0.9432811 & 0.9210336 & 0.8983277 & 0.9018681 & 0.9083115 & 0.6393361 \\
\hline 0.6 & 0.9520790 & 0.9237837 & 0.9043817 & 0.9104366 & 0.9171161 & 0.6641544 \\
\hline 0.8 & 0.9608553 & 0.9264927 & 0.9103943 & 0.9189869 & 0.9259054 & 0.6896130 \\
\hline 1.0 & 0.9696099 & 0.9291618 & 0.9163594 & 0.9275192 & 0.9346793 & 0.7157143 \\
\hline
\end{tabular}

Table 2: Right interval optimal solution of NSE price data

\begin{tabular}{|c|c|c|c|c|c|c|}
\hline$\alpha$ & $R_{1}^{R}$ & $R_{2}^{R}$ & $R_{3}^{R}$ & $R_{4}^{R}$ & $R_{5}^{R}$ & $R_{S}^{R}$ \\
\hline 0.0 & 0.9871737 & 0.9528928 & 0.9297271 & 0.9367207 & 0.9455511 & 0.7746191 \\
\hline 0.2 & 0.9841955 & 0.9486455 & 0.9275596 & 0.9353877 & 0.9414744 & 0.7626536 \\
\hline 0.4 & 0.9804082 & 0.9436260 & 0.9246285 & 0.9332867 & 0.9408539 & 0.7511236 \\
\hline 0.6 & 0.9769325 & 0.9389151 & 0.9219902 & 0.9314823 & 0.9381038 & 0.7389970 \\
\hline 0.8 & 0.9732787 & 0.9340413 & 0.9191825 & 0.9295080 & 0.9363984 & 0.7273088 \\
\hline 1.0 & 0.9696099 & 0.9291618 & 0.9163594 & 0.9275192 & 0.9346793 & 0.7157143 \\
\hline
\end{tabular}

Step 5:

From the Table 1 and Table 2, the maximum reliability is identified with their fluffy membership values of $\alpha$.

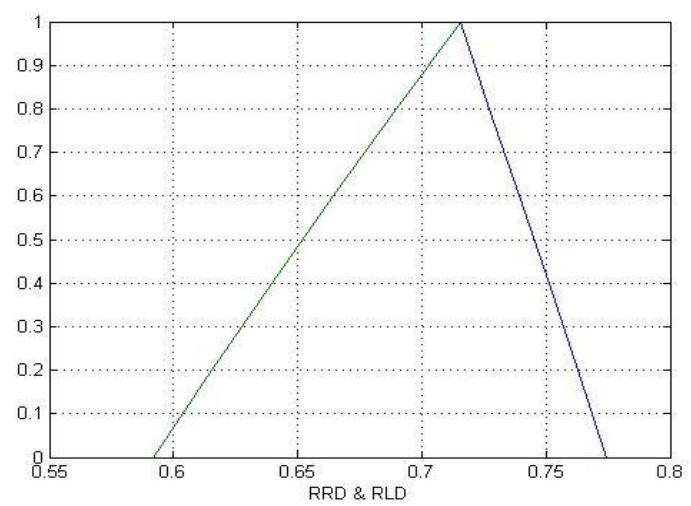

Fig. 1: Interval valued reliability of NSE price data

\section{Conclusion}

The fluffy non-linear programming problem is considered to quantify the most extreme unwavering quality subject to least cost. Table 1 shows the left interval optimum solution of NSE Price data subject to the cost constraints, which identifies that reliability for $\alpha=0.0$ is 0.5916 . Table 2 shows the right interval optimum solution of NSE Price data for ICICI Bank subject to the cost constraints, which identifies that reliability for $\alpha=0.0$ is 0.7746 . Figure 1 shows the interval valued reliability with triangular fluffy number and identify the maximum reliability is $\mathrm{Rs}=0.7157$. This analysis clearly shows that the NSE value of ICICI Bank which is taken for one week is more reliable subject to the price data.

\section{References}

[1] Abdul Razak K \& Rajakumar K (2015), Evaluation of maximum reliability using co-efficient of variance for parallel system model, Journal of Information \& Optimization Sciences, 369(4), 393-403.

[2] Benjamin Epstein \& Ishay Weismann (2008). Mathematical models for system reliability, CRC Press, Bosco Raton.

[3] Ezzatallah BJ, Azam Nozari \& Ali Nadi G (2011), Analyzing fluffy system reliability using confidence interval, World Applied Science Journal, 13(10), 2191-2197.

[4] Lee HM, Fuh CF \& Su JS (2012), Fluffy parallel system reliability analysis based on level $(\lambda, e)$ interval valued fluffy numbers, Internationals Journal of Innovative Computing, Information and Control, 8(8), 5703-5713.

[5] Mahapathra GS, Mahapathra MS \& Roy PK (2011), Fluffy decision-making on reliability of series structure : Fluffy Geometric programming approach, Annals of fluffy Mathematics and Informatics, 10, 1-20.

[6] Nabil Nagas \& Mustapha Nourelfath (2005), Ant system for reliability optimization of a series structure with multiple - choice and budget constraints, Reliability Engineering and System Safety, 87, 1-12.

[7] Prem kumar Gupta \& DS. Hira (1991). Problem in operations research: principles and solutions, S.Chand, New Delhi.

[8] Ruan N \& Sun XL (2006), An exact algorithm for cost minimization in series reliability system with multiple component choices, Applied Mathematics and Computations, 181, 732-74.

[9] Shi Y, Shi X \& Xu Y (2005), Approximate confidence limits of the reliability performance for a cold standby series structure, Journal of Computational and Applied Mathematics, 19, 439-445.

[10] Sung CS \& Cho YK (2000), Reliability optimization of a series structure with multiple- choices and budget constraints, European Journal of operation Research, 127(1), 159-171.

[11] Yuan LZ \& Wang GJ (2007), A geometric process repair model for a series repairable system with $\mathrm{k}$ dissimilar components, Applied Mathematical Modeling, 31, 1997-2007. 